\title{
Ideal Mathematics Teaching Behaviors: A Comparison between the Perspectives of Senior High School Students and their Teachers in Taiwan and Mainland China
}

\author{
Feng-Jui Hsieh ${ }^{1}$, Ting-Ying Wang ${ }^{1 *}$, Qian Chen ${ }^{2}$ \\ ${ }^{1}$ Department of Mathematics, National Taiwan Normal University, TAIWAN \\ 2 School of Mathematics and Software Science, Sichuan Normal University, CHINA
}

Received 10 May 2019 - Revised 5 July 2019 - Accepted 6 July 2019

\begin{abstract}
This study determined perspectives of students and their teachers regarding ideal mathematics teaching using questionnaires. The sample included 2437 Taiwanese and 1141 Chinese senior high school students and their mathematics teachers. Exploratory, confirmatory, and multigroup confirmatory factor analysis were conducted to determine the factors contributing to ideal teaching behaviors. Thirteen factors in six dimensions were identified. Five involved the influence of Western culture and were endorsed (e.g., concrete and life-related in representation); five are inherent in traditional Chinese culture and were endorsed (e.g., detailed illustration in teaching method); and three are inherent in Chinese culture but were less endorsed because of Western influences (e.g., speedy challenge in problem-solving). Few intracultural differences regarding students' and teachers' endorsements were discovered. However, students' higher endorsement of formal and symbolic representation and performance demand in assessment than their teachers' reflected their desire for high academic achievement, which is deeply rooted in Chinese culture.
\end{abstract}

Keywords: assessment, ideal mathematics teaching, problem-solving, representation, student perspective, teaching method

\section{INTRODUCTION}

Teachers' mathematics instruction plays a primary role in students' experience of mathematics at school. Efforts have been made worldwide to determine the characteristics of ideal mathematics teaching (Council of Chief State School Officers, 2011; Lin \& Li, 2009; National Academy for Educational Research, 2016; Pang, 2009). Interest in identifying ideal mathematics teaching in East Asian countries including Taiwan and mainland China has increased internationally because of the high achievements of students in these countries, as revealed by international comparison studies (e.g., the Programme for International Student Assessment [PISA]; OECD, 2016). However, teaching is known to be strongly affected by "culture scripts" (Stigler \& Hiebert, 1999). Studies have revealed that what is considered ideal mathematics teaching differs between Eastern and Western cultures (Bryan, Wang, Perry, Wong, \& Cai, 2007; Kaiser \& Vollstedt, 2007; Perry, 2007; Wang \& Cai, 2007a, 2007b; Wong, 2007) and that perspectives on ideal mathematics teaching can be various in regions with different social norms even if cultural traditions are shared, such as is the case for mainland China and Hong Kong (Cai, Perry, Wong, \& Wang, 2009).

Taiwan and mainland China did not interact much with each other in mathematics teaching and pertinent research until recent decades. However, they both went through mathematics curriculum reforms which were enlightened by Western views of ideal mathematics teaching. Whether these two education systems share similar perspectives on ideal mathematics teaching reflecting the impacts of cultural scripts and whether their perspectives coincide with those rooted in traditional Chinese culture or those newly developed with the influence of Western cultures are still not fully researched.

(C) 2020 by the authors; licensee Modestum Ltd., UK. This article is an open access article distributed under the terms and conditions of the Creative Commons Attribution License (http://creativecommons.org/licenses/by/4.0/).

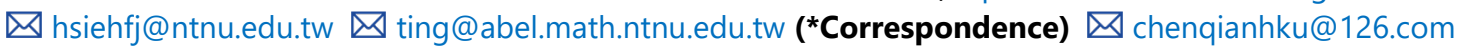




\section{Contribution of this paper to the literature}

- Thirteen factors regarding Taiwanese and Chinese students' and teachers' perspectives on ideal mathematics teaching behaviors were identified, including those rooted in traditional Chinese culture and those influenced by Western culture.

- Regarding the factors rooted in traditional Chinese culture, some were still endorsed (e.g., detailed illustration), whereas others were not because of Western influences (e.g., speedy challenge).

- Compared with the Western educative views, the views from both education systems exhibited no considerable intracultural differences, whereas the comparison between the students' and teachers' views revealed students' higher endorsement on some factors (e.g., formal and symbolic representation) than their teachers.

\section{LITERATURE REVIEW}

Traditional mathematics instruction in Taiwan and mainland China is characterized by teacher-directed, content-oriented, examination-driven, and well-organized whole-class teaching (Chen, 2015; Lin \& Li, 2009). These features are not preferred in the West where ideal mathematics instruction is considered student-centred and process-oriented (Kaiser \& Vollstedt, 2007; Pang, 2009).

Since 1993, Taiwanese curricula have been reformed several times to focus on the development of students' mathematical abilities and literacy rather than on subject-centred learning (Hsieh, 1997). Aligning with the curriculum reform, innovative mathematics teaching has been promoted, shifting the emphasis from teacherdirected examination-driven approaches to student-centred instruction (Lin \& Li, 2009; Lin et al., 2014). This has also been the case for the curriculum reform in mainland China since 2001 (Chen, 2015). Two major perspectives on mathematics instruction are now commonplace in Taiwan and mainland China, one emphasizing traditional teaching involving heavy teacher control, and the other emphasizing Western influences in the form of studentoriented and constructivist-based instruction (Chen, 2015; Hsieh, Shy, \& Wang, 2015; Shao et al., 2013; Yang, 2013).

In the following sections, the mathematics teaching behaviors commonly employed in Taiwan and mainland China are introduced and compared with those used in Western cultures from the perspective of three facets (which are pertinent to in-class instruction) of the construct of mathematics teaching standards that was proposed by the US Council of Chief State School Officers (2011). The three facets are application of contents, instructional strategies, and assessments. This structure coincides with the framework, composed of curriculum, pedagogy, and assessment, proposed by Shepard (2000) to understand classroom practice. Application of contents addresses how teachers introduce and connect mathematical concepts from various perspectives. Instructional strategies relate to the variety of instructional strategies that teachers employ to develop students' mathematical understanding and competence. Finally, assessments refer to the multiple methods of assessment employed to monitor students' learning and guide instruction.

\section{Application of Contents}

Mathematics teachers in Taiwan and mainland China are expected to arrange lessons that connect new material with students' prior knowledge and a real-life context (Lin \& Li, 2009; Wang \& Cai, 2007a). Making internal connections in mathematics is considered an effective approach embedded in traditional Chinese mathematics instruction because of the prevalent belief that mathematics is a coherent system of knowledge. This accords with Western perspectives - the meaningful learning investigated by Ausubel (2000) and the relational comprehension discussed by Skemp (1989). Regarding mathematical representations employed, unlike teachers' advocacy of concrete representations and reluctance to teach mathematics on an abstract level in Western cultures (Cai et al., 2009), middle-school Chinese teachers were reported to believe that understanding some concrete examples does not guarantee understanding at the abstract level, although they do sometimes use concrete examples to help students' understanding (Bryan et al., 2007; Wang \& Cai, 2007a). Instead, students are encouraged to use an abstract and generalized approach to solve mathematical problems and to use symbolic mathematics representation (Cai, 2004). However, the level of difficulty and complexity of symbolic representations employed in Chinese mathematics textbooks since the curriculum reform have decreased compared with representations in older textbooks (Bao, 2004). In Taiwan, a study exploring ideal senior high school mathematics teachers' teaching behaviors revealed that numerical examples, real-life objects, and graphics are often used as meaning sources for mathematical learning, in addition to abstract representations (Tseng, 2008). 


\section{Instructional Strategies}

Mathematics curricula in East Asian countries, including Taiwan and mainland China, cover a broad amount of content at a difficult level, which can only be fulfilled through detailed and well-organized lessons conducted at a fast pace (Cai, 2007; Cai \& Wang, 2006; Wang \& Cai, 2007a). Under these circumstances, clear explanation emphasizing the essential and difficult points of mathematics content is considered to be an effective teaching method in Taiwan and mainland China. Instructive approaches such as guiding students to make observations, comparisons, conjectures, and generalizations, asking critical questions and challenging problems to facilitate students' thinking, and engaging students in problem-solving with multiple solutions have all been considered good teaching methods in these two education systems (Bryan et al., 2007; Li, 2011; Lin \& Li, 2009; Tseng, 2008; Wang \& Cai, 2007a). Hands-on manipulative activities, explorative activities, discussions, small group work, and multimedia have also been employed in Taiwan and mainland China, but to a lesser extent than in Western countries such as Australia, Germany, and the United States (Bryan et al., 2007; Kaiser \& Vollstedt, 2007; Sahin \& Adiguzel, 2014; Tseng, 2008; Wong, 2010; Zhao \& Ma, 2007). Mathematics teachers in East Asian countries recognize the functions of these approaches that are pertinent for long-term activities, but their instruction is often constrained by the stipulated content coverage, students' exam performance, time pressure, and large class sizes. Therefore, they create well-structured lessons that are teacher-led yet student-centred (Bryan et al., 2007; Leu \& Wu, 2005).

\section{Assessments}

The objectives of the curriculum reforms in both Taiwan and mainland China were to change long-used and widespread teaching practices involving intensive practice and endless examinations, which are not preferred in most Western cultures (Cai et al, 2009; Chen, 2015; Farrel \& Grant, 2005; Lin et al., 2014). However, studies demonstrated that middle-school mathematics teachers in mainland China emphasize the importance of practice within ideal mathematics teaching to a much higher degree than teachers in Australia or the United States do (e.g., Bryan et al., 2007). Chen (2015) revealed that some Chinese middle-school mathematics teachers still emphasize examination-based practices, such as mastery quizzes, periodic tests, and considerable drilling with examinationstyle items, to prepare students for success in tests. In some classes, practice involved not a repeatedly rote exercise, but similar problems to help students make general conclusions, as well as varied problems with appropriate difficulty levels and creative elements to help students master and flexibly apply their knowledge (Shao et al., 2013). Teachers face a dilemma of whether to teach solely for exam success, because such success is still required for entering senior high school and higher education (Chen et al., 2012). This was also demonstrated to be the case for Taiwan (Chen, 2008).

\section{THE PRESENT STUDY AND RESEARCH QUESTIONS}

Studies regarding ideal mathematics teaching have employed various research methods with different target populations and have also proposed various attributes of ideal mathematics teaching (e.g., Kaur, 2009; Leong, 2013, 2015; Pang, 2009). However, studies which systematically investigate students' perspectives with the use of a substantial sample size and compare the perspectives with that of their mathematics teachers are few, if not none. The present study intends to contribute to filling this lack.

Investigating teacher perspective can reveal the instruction which is possibly implemented in real mathematics classes because teachers in Taiwan and mainland China are of high quality so that they are likely to conduct teaching behaviors which they consider appropriate (Hsieh et al., 2011; Leung, 2006). Investigating student perspective can inform researchers and educators about student needs and thus refine student-centred views of teaching (Kane \& Maw, 2005; Lee, Kim, \& Chan, 2015; Smith \& Gorard, 2006) that have been promoted in innovative mathematics instruction following the curriculum reforms in Taiwan and mainland China. Because of the teacherdirected view embedded in traditional Chinese culture, the power between students and teachers is unbalanced in these two education systems. Students have no opportunity to evaluate their mathematics teachers, and thus such teachers have no opportunity to improve their mathematics teaching through listening to students' opinions. Thus, this study uses student perspective as the base and makes the comparison between the perspectives of the students and their teachers to produce these opportunities. Furthermore, the comparison between Taiwan and mainland China can provide researchers the opportunities to reveal implicit characteristics in these two education systems which have various social norms but share similar traditional cultural backgrounds.

The present study investigated the following research questions:

(1) What factors contribute to the perspectives of senior high school students in Taiwan and mainland China regarding ideal mathematics teaching behaviors?

(2) What are the differences between Taiwanese and mainland Chinese senior high school students' and teachers' perspectives on ideal mathematics teaching behaviors? 


\section{METHODS}

\section{Instrument}

A questionnaire to determine students' perspectives on ideal mathematics teaching was initially developed in Taiwan by conducting two pilot studies. Through the two studies, mathematics teaching dimensions (for example, mathematical representation) and teaching-behavior items specific to the dimensions were obtained.

The first pilot study collected experts' perspectives on what ideal mathematics teachers should do and how they should do it; the perspectives were obtained through expert consultations and ten focus group discussions. The participants in the first three group discussions were six high school mathematics teachers with master's degrees and four PhD students. In these three group discussions, the initial framework of the mathematics teaching dimensions and the corresponding ideal teaching behaviors was developed. Experts were then asked to evaluate the resultant framework, and these experts included 15, 13, and 13 educators in the fields of mathematics, mathematics pedagogy, and general pedagogy, respectively, and 12 school-based supervisors of preservice mathematics teachers. The participants in the fourth group discussion were 43 expert high school mathematics teachers from 43 schools. They are officially recognized by Taiwanese city governments as the representatives of mathematics teachers in their schools. The participants in the remaining six discussions were 22 expert high school mathematics teachers in compulsory education advisory groups. These groups are operated by Taiwanese national and city governments, and their members are responsible for guiding other mathematics teachers. The final seven group discussions were conducted to obtain the expert teachers' perspectives on ideal mathematics teaching behaviors (Hsieh, 2012).

The second pilot study collected students' perspectives. Questionnaires composed of open-ended questions were used to survey 238 high school students. The mathematics teachers of these six classes had reputations of being good teachers. Two forms of questionnaire were used. One form asked students to write down the teaching behaviors of their mathematics teacher; for example, three things that their teachers did during mathematics instruction that helped and three things that did not help their learning mathematics and the reasons why. The other form asked similar questions but focused on what excellent mathematics teachers should do, rather than what their teachers did. The two forms were designed to record both practical and imaginative pictures of the students' perspectives on ideal teaching behaviors. The students in each class were randomly split into two groups and each group filled out one form.

The data collected in the pilot studies were analyzed through a content analysis to determine the mathematics teaching dimensions and the teaching behaviors specific to each dimension.

The teaching behaviors were used as dichotomous items (give " $\checkmark$ " to those a great senior high school mathematics teacher should do and " $x$ " to those should not) and were organized according to the dimensions to form the formal questionnaire of the present study. To compare Taiwan with mainland China, the questionnaire was then validated by the Chinese research team by conducting two group discussions involving one teacher educator in the field of mathematics education, four high school teachers, and two graduate students. In the two group discussions, every item was discussed and its wording and appropriateness for the Chinese mathematics instructional context assessed. The questionnaire was then administered to 150 high school students (one junior and one senior high school class), and six junior and six senior high school students were interviewed. The responses obtained from the questionnaire survey and interviews were used to further assess and modify the wording and appropriateness of the items. Finally, all the items in the Taiwanese version of the questionnaire were retained, but some wordings were modified without changing the meanings to fit language use in mainland China.

Six dimensions in the three facets introduced by the US Council of Chief State School Officers (2011) application of contents, instructional strategies, and assessments - were included in the present study (see the first column in Table 1). The six dimensions and the facets they belong to are as follows: handling teaching materials and representation were included in the facet application of contents; teaching process, teaching method, and problem solving were included in the facet instructional strategies; and assessment was included in the facet assessments. The six dimensions comprised (in sequence) 13, 11, 8, 16, 15, and 13 items (the examples are provided in the section of results). The examples of the stems that prompted the items are as follows: "When representing mathematical concepts and ideas, when proper, a great senior high school mathematics teacher should...", "Regarding teaching behaviors for problem solving in class, a great senior high school mathematics teacher should...", and "In order to evaluate students and understand the students' learning conditions, a great senior high school mathematics teacher should..." 
Table 1. Factor models for the six dimensions within the three facets

\begin{tabular}{|c|c|c|c|c|}
\hline Dimensions of facets & Model & Factor & $\begin{array}{l}\text { Number of } \\
\text { items }\end{array}$ & Removed items \\
\hline \multicolumn{5}{|l|}{ Application of contents } \\
\hline \multirow[b]{2}{*}{ Handling teaching material } & \multirow[b]{2}{*}{$\begin{array}{l}\text { Two-factor } \\
\text { model }\end{array}$} & Simplification and concreteness & 4 & \multirow{2}{*}{$\begin{array}{l}3 \text { items were removed because } \\
\text { they had small factor loadings } \\
2 \text { items were removed because } \\
\text { of cross-loading }\end{array}$} \\
\hline & & Connecting and meaning & 4 & \\
\hline \multirow[b]{2}{*}{ Representation } & \multirow[b]{2}{*}{$\begin{array}{l}\text { Two-factor } \\
\text { model }\end{array}$} & Formal and symbolic representation & 5 & \multirow{2}{*}{$\begin{array}{l}-1 \text { item was removed because it } \\
\text { had a small factor loading }\end{array}$} \\
\hline & & $\begin{array}{l}\text { Concrete and life-related } \\
\text { representation }\end{array}$ & 5 & \\
\hline \multicolumn{5}{|l|}{ Instructional strategies } \\
\hline \multirow{2}{*}{ Teaching process } & \multirow{2}{*}{$\begin{array}{l}\text { Two-factor } \\
\text { model }\end{array}$} & Concept connecting and firming & 4 & \\
\hline & & Outlining and problem-solving & 4 & \\
\hline \multirow{3}{*}{ Teaching method } & \multirow{3}{*}{$\begin{array}{l}\text { Three-factor } \\
\text { model }\end{array}$} & Detailed illustration & 5 & \\
\hline & & Questioning & 3 & \\
\hline & & Long-term task & 8 & \\
\hline \multirow{2}{*}{ Problem solving } & \multirow{2}{*}{$\begin{array}{l}\text { Two-factor } \\
\text { model }\end{array}$} & Multiple heuristics & 9 & \multirow{2}{*}{$\begin{array}{l}3 \text { items were removed because } \\
\text { of cross-loading }\end{array}$} \\
\hline & & Speedy challenge & 3 & \\
\hline \multicolumn{5}{|l|}{ Assessments } \\
\hline \multirow{2}{*}{ Assessment } & \multirow{2}{*}{$\begin{array}{l}\text { Two-factor } \\
\text { model }\end{array}$} & Performance demand & 5 & \\
\hline & & Comprehension diagnoses & 8 & \\
\hline
\end{tabular}

\section{Participants}

The samples in Taiwan and mainland China consisted of 2437 and 1141 senior high school students, respectively. The Taiwanese students were from 61 classes in 30 senior high schools in 20 of the 22 cities in Taiwan (the schools in the remaining two cities did not agree to participate in the survey), whereas the Chinese students were from 23 classes in 10 senior high schools in four cities in Sichuan Province. The schools in each city were randomly selected, and classes were randomly chosen in the selected schools. Of the Taiwanese students, $23.8 \%$ were 10 th graders, $40.8 \%$ were 11 th graders, and $35.4 \%$ were 12 th graders; additionally, $50 \%$ were girls and $50 \%$ were boys. Of the Chinese students, $28.6 \%, 51.5 \%$, and $19.9 \%$ were 10 th, 11 th, and 12 th graders, respectively; $57 \%$ and $43 \%$ were girls and boys, respectively. The mathematics teachers of these classes were also included in the present study so that comparison with the students could be made.

The students in China and the teachers in both education systems filled out all items in the questionnaire. In Taiwan, the students were randomly split into two and the items were divided into two questionnaires. Each half of the students filled out one form of the questionnaire, to reduce the required answering time, thereby making the students less hesitant and consequently increasing their willingness to cooperate.

\section{Data Analysis}

To determine the factors contributing to ideal mathematics teaching behaviors in the students' perspectives, this study performed exploratory factor analysis (EFA) on the Taiwanese and Chinese students' responses to the questionnaire items (a great senior high school mathematics teacher should do $=$ " $\checkmark$ " $=1$ and a great senior high school mathematics teacher should not do $=" x "=0$ ). EFA for categorical items was separately performed on each of the aforementioned six dimensions with Mplus 6.12. This study applied confirmatory factor analysis (CFA) for categorical items separately for each education system to examine the validity of the latent construct produced by EFA. These baseline models were integrated into a multigroup CFA model to test measurement configural invariance. To ensure the underlying latent factors were measured in the same way for the two education systems, the invariance of factor loadings between them were then tested (weak measurement invariance). When the invariances were confirmed, comparison of the scales of the two education systems was meaningful (Wang \& Wang, 2012). A robust weighted least-squares estimator was applied when EFA and CFA were conducted because it is typically considered robust for nonnormal data (Flora \& Curran, 2004). The sampled students were randomly split into two halves; one half for EFA and the other half for CFA (including multigroup CFA).

The fit indices employed for the overall model fit tests of EFA and CFA were the (a) comparative fit index (CFI), (b) Tucker-Lewis index (TLI), and (c) root mean square error of approximation (RMSEA). A factor model was adopted in this study when the CFI and TLI were $\geq 0.9$, indicating a good fit, and RMSEA was $\leq 0.08$, indicating a reasonable approximate fit (Wang \& Wang, 2012; Williams, Brown, \& Onsman, 2010). Furthermore, model comparisons using the $\chi^{2}$ difference test were conducted using Mplus to determine the optimal model out of the 
Table 2. Results of the weak measurement invariance model of handling teaching material

\begin{tabular}{lcc}
\hline \multirow{2}{*}{ No. Item } & \multicolumn{1}{c}{ Standardized factor loading } \\
\cline { 2 - 3 } & \multicolumn{1}{c}{ Taiwan } & \multicolumn{1}{c}{ Mainland China } \\
\hline HM1 Apply simple computations to introduce formulas and properties & 0.685 & 0.544 \\
\hline HM2 Provide many daily-life examples when teaching new ideas & 0.586 & 0.465 \\
\hline HM3 Start from basic concepts so we can develop a full picture of the concepts & 0.645 & 0.512 \\
\hline HM4 $\begin{array}{l}\text { Provide many similar problems as examples to help us have a better understanding of } \\
\text { the formula and concepts }\end{array}$ & 0.700 & 0.556 \\
\hline \multicolumn{1}{c}{ Factor 2: Connecting and meaning } & 0.742 \\
\hline HM5 Extend and connect mathematical concepts from those that we have already learned & 0.796 & 0.619 \\
\hline HM6 $\begin{array}{l}\text { Formulate connections and comparisons among new mathematical concepts and other } \\
\text { already learned concepts }\end{array}$ & 0.665 & 0.620 \\
\hline HM7 Arrange examples in such a way as to help us understand concepts step-by-step & 0.666 \\
\hline HM8 $\begin{array}{l}\text { The prerequisite concepts needed would have been introduced prior to teaching new } \\
\text { concepts }\end{array}$ & 0.603 & 0.561 \\
\hline
\end{tabular}

Note. The three items removed because of small factor loadings are "Pay more attention to textbooks and workbooks than outline or handouts" (HM9), "When choosing or arranging teaching materials, focus on the derivations of the formulas and properties rather than just the statements of them" (HM10), and "Rather than heavily illustrate the meaning of concepts, provide many examples" (HM11). The two items removed because of cross-loading are "Clearly illustrate the meaning of mathematical concepts" (HM12) and "Do not only use questions from the textbooks, workbooks, and handouts, but instead use any questions that are appropriate" (HM13). Fit statistics of the model: CFI=0.987, TLI=0.983, and RMSEA=0.013. The Cronbach alpha coefficients of factor 1 and factor 2 are 0.526 and 0.562 respectively, indicating a moderately reliable scale.

configural model and the weak measurement invariance model. Changes in the CFI were also used to determine the superior model (Wang \& Wang, 2012). Adequate factor loadings were defined as $\geq 0.3$ (Wang \& Wang, 2012; Williams, Brown, \& Onsman, 2010). Items with factor loadings of $<0.3$ or cross-loading would be deleted, and the EFA and CFA would be rerun.

To explore Taiwanese and Chinese students' and teachers' perspectives on ideal teaching behaviors, for each group, this study computed a mean of the percentages of checking of the teaching behaviors in each teachingbehavior factor as the endorsement level of that factor. Both students' and teachers' perspectives were organized according to the factors obtained from student data to reflect the student-centred view. To investigate whether the students' endorsements differed among factors, from those of their teachers, or between education systems, a paired sample $t$-test and analysis of variance with post hoc tests were conducted to compare the group means of the factors. In addition to the $p$-value, Cohen's rule of thumb for effect size (ES) interpretation was used to indicate practical significance. Values exceeding $0.2,0.5$, and 0.8 indicate a small, medium, and large ES, respectively (Cohen, 1992).

\section{RESULTS}

\section{Factor Models of Ideal Mathematical Teaching Behaviors from Perspective of Senior High School Students}

Factor models for each of the six dimensions (included in the three facets) produced by EFA and confirmed by CFA are presented in Table 1. For all dimensions, the final EFA models, CFA models for each education system, and multigroup CFA models for measurement configural invariance and weak measurement invariance adequately fit the data, according to the fit statistics (CFI $\geq 0.9, T L I \geq 0.9$, RMSEA $\leq 0.08$, and all factor loadings $\geq 0.3$ ). Model comparison tests based on the $\chi^{2}$ differences between the configural models and weak measurement invariance models revealed no significant differences between the two models for each dimension, with $p>.05$ ( $p=0.051-0.737)$. Additionally, the difference between the CFIs of the two models was less than 0.01 . These results indicated that the model for weak measurement invariance could not be rejected. Thus, the underlying latent factors were measured in the same way for both the Taiwan and mainland China samples, and comparison of the two education systems' scales was meaningful.

Handling teaching material - comprising selection of available materials, deciding upon the trajectories of mathematics topics, and determination of depth and breadth of topics - was captured by two factors: simplification and concreteness and connecting and meaning (see Table 2). Simplification and concreteness represented a group of teaching behaviors that started with basic ideas and simple calculations and provided examples to give students concrete experience of abstract mathematical ideas. The exemplified items were "Start from basic concepts so students can develop a full picture of the concepts" and "Provide many similar problems as examples to help students have a better understanding of the formula and concept." Connecting and meaning represented a group of teaching behaviors that arranged ideas and examples to connect new concepts with previously learned material, 
Table 3. Results of the weak measurement invariance model of representation

\begin{tabular}{|c|c|c|c|}
\hline \multirow{2}{*}{ No. } & \multirow{2}{*}{ Item } & \multicolumn{2}{|c|}{ Standardized factor loading } \\
\hline & & Taiwan & Mainland China \\
\hline \multicolumn{4}{|c|}{ Factor 1: Formal and symbolic representation } \\
\hline R1 & $\begin{array}{l}\text { Use a formal approach (e.g., definitions) to present new concepts and ideas as much as } \\
\text { possible }\end{array}$ & 0.698 & 0.671 \\
\hline $\mathrm{R} 2$ & Use actual numbers to present new concepts and ideas as much as possible & 0.483 & 0.464 \\
\hline R3 & Use proofs to present new concepts and ideas as much as possible & 0.531 & 0.510 \\
\hline R4 & Use abstract symbols to present new concepts and ideas as much as possible & 0.702 & 0.674 \\
\hline R5 & Use formulas to present new concepts and ideas as much as possible & 0.756 & 0.726 \\
\hline \multicolumn{4}{|c|}{ Factor 2: Concrete and life-related representation } \\
\hline R6 & Use stories to present new concepts and ideas as much as possible & 0.629 & 0.597 \\
\hline R7 & Use examples to present new concepts and ideas as much as possible & 0.402 & 0.382 \\
\hline R8 & $\begin{array}{l}\text { Use demonstrations with objects in the surroundings to present new concepts and } \\
\text { ideas as much as possible }\end{array}$ & 0.848 & 0.805 \\
\hline R9 & Use appropriate metaphors to present new concepts and ideas as much as possible & 0.795 & 0.755 \\
\hline R10 & Use things in real life to present new concepts and ideas as much as possible & 0.945 & 0.897 \\
\hline
\end{tabular}

Table 4. Results of the weak measurement invariance model of teaching process

\begin{tabular}{|c|c|c|c|}
\hline \multirow{2}{*}{ No. } & \multirow{2}{*}{ Item } & \multicolumn{2}{|c|}{ Standardized factor loading } \\
\hline & & Taiwan & Mainland China \\
\hline \multicolumn{4}{|c|}{$\begin{array}{ll}\text { Factor 1: Concept connecting and firming } \\
\end{array}$} \\
\hline TP1 & $\begin{array}{l}\text { Require us to preview the content to be taught beforehand so we can know in advance } \\
\text { which parts is difficult to understand }\end{array}$ & 0.526 & 0.500 \\
\hline TP2 & Classify and organize the concepts after teaching them & 0.652 & 0.621 \\
\hline TP3 & $\begin{array}{l}\text { Give us a few practice problems in class to solve after teaching a concept or solving } \\
\text { example questions }\end{array}$ & 0.647 & 0.616 \\
\hline TP4 & Teach concepts alongside problems & 0.628 & 0.598 \\
\hline \multicolumn{4}{|c|}{ Factor 2: Outlining and problem solving } \\
\hline TP5 & $\begin{array}{l}\text { Explain the correct concept to be used before a new lesson or before discussing math } \\
\text { problems }\end{array}$ & 0.770 & 0.750 \\
\hline TP6 & $\begin{array}{l}\text { Pause between appropriate part of the class to allow us to reflect on what has been } \\
\text { taught }\end{array}$ & 0.470 & 0.457 \\
\hline TP7 & Outline the key points and then explain them & 0.593 & 0.577 \\
\hline TP8 & Properly review previous content before starting a new lesson & 0.603 & 0.587 \\
\hline
\end{tabular}

leading to meaningful learning. The examples of the items were "Extend and connect mathematical concepts from those that students have already learned" and "Formulate connections and comparisons among new mathematical concepts and other already learned concepts." Representation, which is relevant to the selection of suitable mathematics representations for students, was captured by two factors: formal and symbolic representation and concrete and life-related representation (see Table 3). Formal and symbolic representation comprised representations involving formal or structural means of representing mathematical ideas such as "abstract symbols," "formulas," and "definitions." Concrete and life-related representation comprised the representations characterized by concreteness such as "examples," "objects in the surroundings," and "metaphors."

Teaching process, pertinent to the time points at which certain teaching behaviors are employed such as connecting to prior knowledge or providing exercises, was captured by two factors: concept connecting and firming and outlining and problem solving (see Table 4). Concept connecting and firming represented teaching processes that emphasized the development of students' understanding of mathematical concepts by connecting concepts to be learned to their learnt ideas and firming up the newly learnt concepts in their minds with examples. Two such items were "Require students to preview the content to be taught beforehand so they are can know in advance which parts will be difficult to understand" and "Teach concepts alongside problems." Outlining and problem solving represented teaching processes that emphasized the development of students' mathematical problem-solving skills by pointing out the key and required concepts in learning and solving problems. The exemplified items were "Outline the key points and then explaining them" and "Explain the correct concept to be used before a new lesson or before discussing math problems." Teaching method, which relates to the various ways of introducing 
Table 5. Results of the weak measurement invariance model of teaching method

\begin{tabular}{|c|c|c|c|}
\hline \multirow{2}{*}{\multicolumn{2}{|c|}{ No. Item }} & \multicolumn{2}{|c|}{ Standardized factor loading } \\
\hline & & Taiwan & Mainland China \\
\hline \multicolumn{4}{|c|}{ Factor 1: Detailed illustration } \\
\hline TM1 & Use simple and clear words to introduce new ideas & 0.489 & 0.486 \\
\hline TM2 & Guide us in observation and induction to develop our concepts & 0.707 & 0.703 \\
\hline TM3 & Emphasize critical ideas repeatedly in class & 0.396 & 0.393 \\
\hline TM4 & Explain to clarify our confusion and doubts & 0.693 & 0.689 \\
\hline TM5 & Introduce new concepts from easy to difficult levels & 0.603 & 0.599 \\
\hline \multicolumn{4}{|c|}{ Factor 2: Questioning } \\
\hline TM6 & Present incorrect ideas or solutions for us to figure out & 0.344 & 0.313 \\
\hline TM7 & $\begin{array}{l}\text { Pose questions about what is being taught and ask us to answer them, enabling us to } \\
\text { learn }\end{array}$ & 0.669 & 0.610 \\
\hline TM8 & Before explaining to us, ask us to guess possible answers to some questions in class. & 0.693 & 0.632 \\
\hline \multicolumn{4}{|c|}{ Factor 3: Long-term task } \\
\hline TM9 & Provide hands-on activities for us to understand mathematics in class & 0.761 & 0.693 \\
\hline TM10 & $\begin{array}{l}\text { Ask us to solve problems on the board to enable us to learn how others solve the same } \\
\text { problems }\end{array}$ & 0.573 & 0.521 \\
\hline TM11 & 1 Provide opportunities for students' discussion in class & 0.743 & 0.676 \\
\hline TM12 & 2 Ask us to explore new concepts or ideas before providing instruction & 0.623 & 0.567 \\
\hline TM13 & 3 Use well-designed worksheets to teach & 0.596 & 0.542 \\
\hline TM14 & 4 Allow us to learn through games in class & 0.773 & 0.703 \\
\hline TM15 & 5 Employ small group learning when applicable & 0.903 & 0.822 \\
\hline TM16 & 5 Switch between various teaching methods rather than use only one method & 0.593 & 0.540 \\
\hline
\end{tabular}

mathematics topics, was captured by three factors: detailed illustration, questioning, and long-term task (see Table 5). Detailed illustration represented teaching behaviors that instructing mathematical ideas from the easy to the difficult using simple words and guiding students to observe and induct such ideas. The exemplified items were "Use simple and clear words to introduce new ideas" and "Explain the new concept from easy to difficult levels." Questioning represented teaching behaviors that required students to conjecture and answer the questions posed in class. The items included "Pose questions about what is being taught and ask students to answer them, enabling them to learn" and "Before explaining to students, ask them to guess the possible answers to the questions in class." Long-term task represented teaching behaviors that required students to participate in learning activities that take time to complete, such as manipulations, explorations, discussions, games, and small group work. The items included "Provide hands-on activities for students to understand mathematics in class" and "Ask students to explore the new concept or ideas before providing instruction." Problem solving, which refers to the various ways of teaching problem solving, was captured by two factors: multiple heuristics and speedy challenge (see Table 6). Multiple heuristics represented teaching behaviors that employed various heuristic strategies in the four steps of problem solving (Polya, 1973), such as "Require students to think how to solve the problem before it is explained," "Explain how to think according to given conditions before carrying out problem solving", "Analyze the problem with students to gradually deduce the answer," and "After the problem was solved, ask students to look back at how the problem was solved." Speedy challenge represented teaching behaviors that involved immediately demonstrating how to solve a problem, with the omission of unimportant steps, and solving challenging problems in various ways. The exemplified items were "Solve a problem immediately after presenting it to not waste time" and "Only go over important steps rather than every single one when solving a problem."

Assessment, relevant to the various approaches of conducting assessments, was captured by two factors: performance demand and comprehension diagnoses (see Table 7). Performance demand involved assessments that provided students with heavy practice to meet the demand for high academic performance. Two such items were "Organize many quizzes to make students practice more and become aware of the content that is not well grasped" and "Meet the teaching schedule 2 weeks ahead, and start to request that students practice with problems to prepare for midterm or final exams." Comprehension diagnoses involved assessments that determined student comprehension through multiple approaches. Two exemplified items were "Raise some questions about basic concepts to test whether they are well grasped by the students" and "Not only conduct a paper and pencil test but also conduct other approaches, such as having students answer questions when called upon, to evaluate students." 
Table 6. Results of the weak measurement invariance model of problem solving

\begin{tabular}{|c|c|c|c|}
\hline \multirow{2}{*}{\multicolumn{2}{|c|}{ No. Item }} & \multicolumn{2}{|c|}{ Standardized factor loading } \\
\hline & & Taiwan & Mainland China \\
\hline \multicolumn{4}{|c|}{$\begin{array}{ll}\text { Factor 1: Multiple heuristics } \\
\end{array}$} \\
\hline PS1 & Allow us to use our own methods to solve problems, not just the teacher's own & 0.529 & 0.474 \\
\hline PS2 & Provide us hints before actually solving a problem to ease our loading & 0.398 & 0.357 \\
\hline PS3 & Identify crucial points and keywords of a problem when solving it & 0.731 & 0.655 \\
\hline PS4 & Analyze the problem with us to gradually deduce the answer & 0.675 & 0.604 \\
\hline PS5 & Require us to think how to solve a problem before it is explained & 0.718 & 0.643 \\
\hline PS6 & Explain how to think according to given conditions before carrying out problem-solving & 0.866 & 0.775 \\
\hline PS7 & Use different approaches to tackle a problem which we have trouble understanding & 0.467 & 0.419 \\
\hline PS8 & After the problem was solved, asking us to look back at how the problem was solved & 0.722 & 0.647 \\
\hline PS9 & Compare and synthesize various problems and various problem types & 0.787 & 0.705 \\
\hline \multicolumn{4}{|c|}{$\begin{array}{ll} & \text { Factor 2: Speedy challenge } \\
\end{array}$} \\
\hline PS10 & 0 Take a challenging problem as an example and solve it with different methods & 0.529 & 0.551 \\
\hline PS11 & 1 Only go over important steps rather than every single one when solving a problem & 0.538 & 0.560 \\
\hline$\overline{\mathrm{PS} 12}$ & 2 Solve a problem immediately after presenting it to not waste time & 0.724 & 0.754 \\
\hline
\end{tabular}

Table 7. Results of the weak measurement invariance model of assessment

\begin{tabular}{|c|c|c|c|}
\hline \multirow{2}{*}{ No. } & \multirow{2}{*}{ Item } & \multicolumn{2}{|c|}{ Standardized factor loading } \\
\hline & & Taiwan & Mainland China \\
\hline \multicolumn{4}{|c|}{ Factor 1: Performance demand } \\
\hline A1 & $\begin{array}{l}\text { Organize many quizzes to make us practice more and become aware of the content that } \\
\text { is not well grasped }\end{array}$ & 0.662 & 0.621 \\
\hline $\mathrm{A} 2$ & Arrange some difficult problems to warn us & 0.508 & 0.477 \\
\hline A3 & $\begin{array}{l}\text { Give a quiz after the teaching of a section is completed to test whether it's well grasped } \\
\text { by us }\end{array}$ & 0.679 & 0.638 \\
\hline A4 & Arrange a lot of homework for us to practice on & 0.759 & 0.713 \\
\hline A5 & $\begin{array}{l}\text { Meet the teaching schedule } 2 \text { weeks ahead, and start to request that students practice } \\
\text { with problems to prepare for midterm or final exams }\end{array}$ & 0.496 & 0.466 \\
\hline \multicolumn{4}{|c|}{ Factor 2: Comprehension diagnoses } \\
\hline A6 & $\begin{array}{l}\text { Walk around the classroom during lessons to determine the students' level of } \\
\text { understanding }\end{array}$ & 0.584 & 0.596 \\
\hline A7 & Raise some questions about basic concepts to test whether they are well grasped by us & 0.472 & 0.482 \\
\hline A8 & $\begin{array}{l}\text { Not only conduct a paper and pencil test but also conduct other approaches, such as } \\
\text { having students answer questions when called upon, to evaluate us }\end{array}$ & 0.653 & 0.667 \\
\hline A9 & $\begin{array}{l}\text { Constantly make sure whether we understand the content being taught. For example, ask } \\
\text { us to raise our hands if we do }\end{array}$ & 0.568 & 0.580 \\
\hline A10 & Solidly discuss assignments and tests and require us to correct the error & 0.639 & 0.652 \\
\hline A11 & Explain and discuss the problems that were incorrectly answered by most students & 0.432 & 0.441 \\
\hline A12 & $\begin{array}{l}\text { Assign similar problems to the questions we get wrong after finishing discussion of those } \\
\text { questions }\end{array}$ & 0.528 & 0.539 \\
\hline A13 & $\begin{array}{l}\text { Ask students to teach each other how to arrive at solutions for the math problems that } \\
\text { were incorrectly done by them }\end{array}$ & 0.524 & 0.535 \\
\hline
\end{tabular}

Note. Fit statistics of the model: $\mathrm{CFI}=0.927, \mathrm{TLI}=0.918$, and RMSEA $=0.036$. The Cronbach alpha coefficients of factor 1 and factor 2 are 0.549 and 0.571 respectively, indicating a moderately reliable scale.

\section{Comparison of the Perspectives of Senior High School Students with those of their Teachers on Ideal Mathematical Teaching Behaviors in Taiwan and Mainland China}

Figure 1 illustrates the group means for student and teacher perspectives on ideal mathematics teaching behaviors in the two dimensions of the application of contents facet. Regarding handling teaching material, the means of the students in the two education systems shared the same pattern. The students endorsed both connecting and meaning simplification and concreteness, and they endorsed the former factor to a higher degree than they did the latter factor $(p<.01$; ES $=0.25-0.33)$. The means of the teachers in the two education systems also shared the same pattern with that of the students $(p<.01 ; \mathrm{ES}=0.60-1.00)$. Regarding representation, both sets of students endorsed concrete and life-related representation rather than formal and symbolic representation, as did their teachers $(p<.01$; 


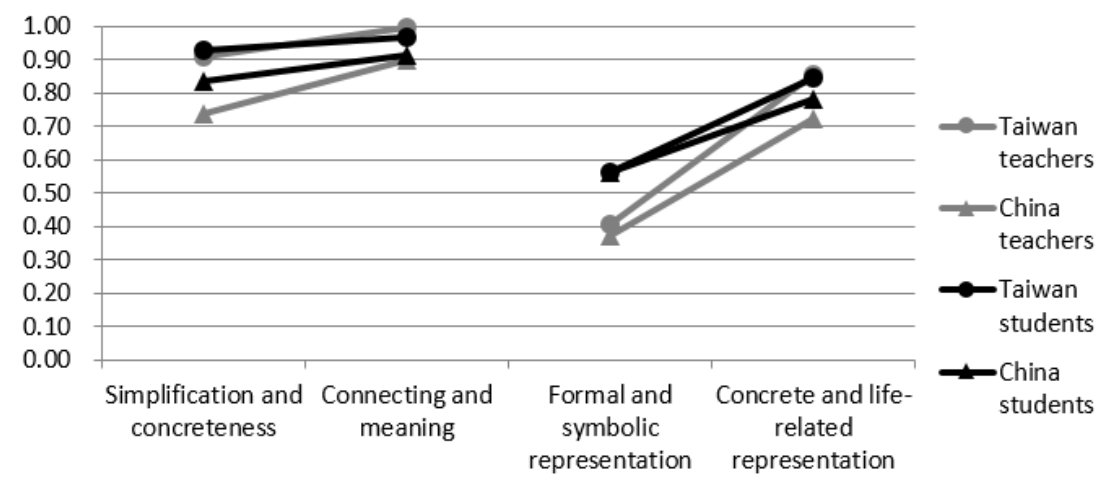

Handling teaching material

Representation

Figure 1. Means of factors in the dimensions within the application of contents facet

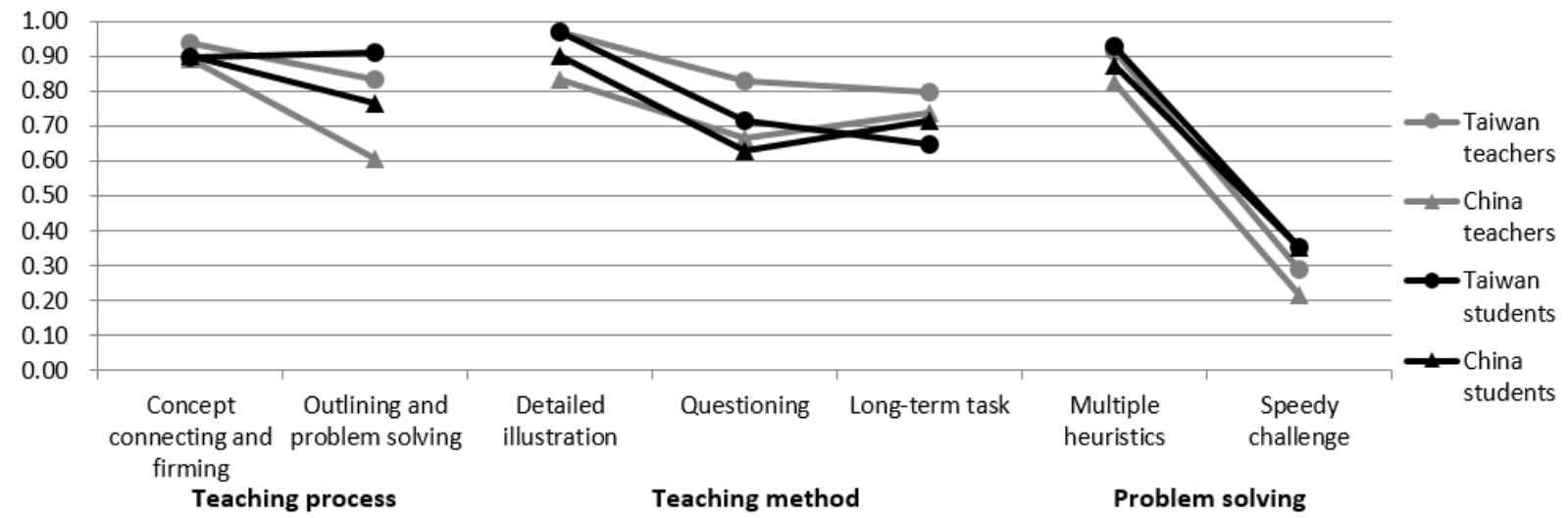

Figure 2. Means of factors in the dimensions within the instructional strategies facet

$\mathrm{ES}=0.60-1.60$ ). For the two education systems, neither the students nor teachers endorsed formal and symbolic representation (means < 0.60; Hsieh, 2012), however, the students endorsed this factor more than their teachers did $(p<.05 ; \mathrm{ES}=0.56-0.67)$.

Figure 2 displays the group means of factors in the dimensions of the instructional strategies facet. Regarding the teaching process dimension, both concept connecting and firming and outlining and problem-solving were endorsed by the students and their teachers in the two education systems. With the exception of Taiwanese students whose means of the two factors were not significantly different, all subjects endorsed concept connecting and firming more than they did outlining and problem-solving within $(p<.01 ; \mathrm{ES}=0.48-0.88)$. Regarding teaching method, Taiwanese and mainland Chinese students and their teachers endorsed detailed illustration, questioning and long-term tasks. However, the means of the two sets of students did not follow the same pattern. Both sets valued detailed illustration the most; however, the second and third most favoured factors among Taiwanese students were questioning and long-term tasks, respectively, with the order reversed for the Chinese students (the differences of any two factors: $p<.01 ; E S=0.20-1.18$ ). Means for the teachers of neither education system shared the same pattern as their students, but the two teacher sets did endorse similarly. The teachers endorsed detailed illustration more than they did the other two factors $(p<.01$; ES=0.61-0.74), but the means of these two factors were not significantly different. Regarding problem solving, the students in both education systems endorsed multiple heuristics rather than speedy challenge, as did their teachers $(p<.01 ; \mathrm{ES}=1.47-2.56)$. The means of the students and teachers were lower than 0.60 , revealing that neither groups endorsed speedy challenge.

Figure 3 illustrates the group means for student and teacher perspectives on ideal mathematics teaching behaviors regarding assessment. The students in both education systems endorsed comprehension diagnoses rather than performance demand, as did their teachers ( $p<.01$; ES=1.00-2.77). The means of the students and teachers were lower than 0.60, revealing that neither endorsed performance demand. Additionally, the students of both education systems endorsed performance demand more than their teachers did $(p<.05 ; \mathrm{ES}=0.53-0.69)$. 


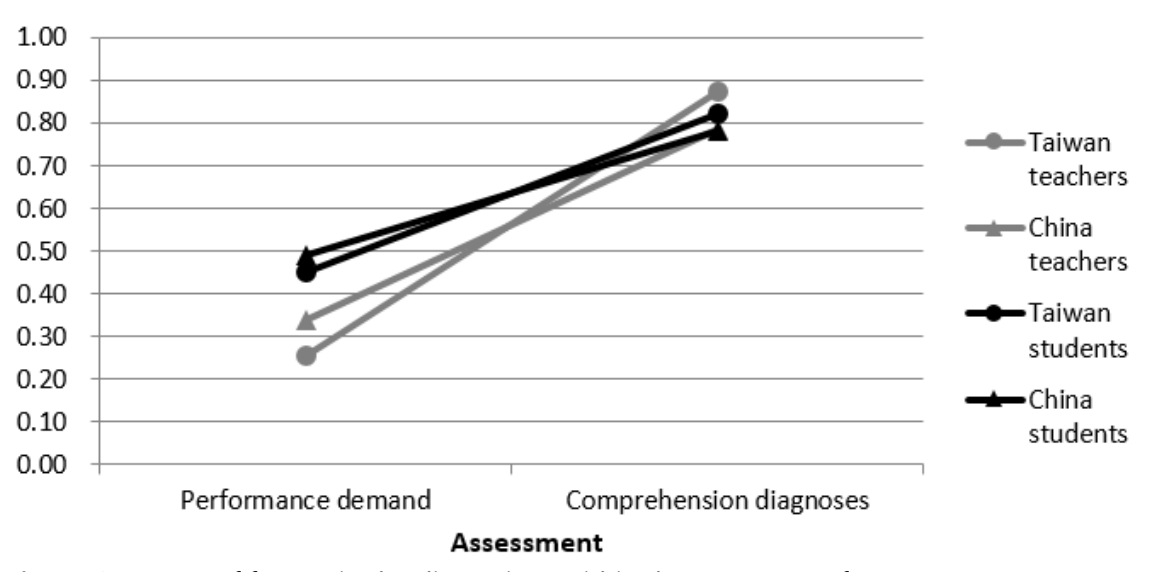

Figure 3. Means of factors in the dimensions within the assessment facet

\section{DISCUSSION}

The results of this study regarding ideal mathematics teaching behaviors in three facets-application of contents, instructional strategies, and assessments-are discussed in this section through a within-culture comparison of Taiwan and mainland China and through a comparison between these two education systems in East Asia and Western cultures to deepen our understanding of the findings of the present study.

\section{Application of Contents}

In East Asian countries, including Taiwan and mainland China, mathematics is traditionally viewed as a coherent system of knowledge using abstract symbols, and mathematics education in schools typically emphasizes knowledge acquisition. Western cultures, however, place more emphasis on the process view, which considers mathematics as a process with which to deal with reality and focuses more on the process of doing mathematics (Leung, 2001; Wang \& Cai, 2007b). Such Western views have been promoted in the mathematics curriculum reforms of both Taiwan and mainland China (Ministry of Education, 2008; Zhao \& Ma, 2013), and the findings of this study regarding the application of contents facet reflect the influence on the reforms. The senior high school students from both education systems and their teachers considered the use of concrete and life-related materials and representations as ideal mathematics teaching behaviors. The relatively low endorsement of formal and symbolic representation in this study also reflects the decrease in symbolic operations dictated in the curriculum reforms (Bao, 2004). However, the use of symbolic representations is inevitable in the demanding mathematics curriculum at senior high school level and within the competitive national university entrance examinations. This may have been the cause of the students' higher endorsement of this factor than their teachers' in both education systems wherein high academic achievements are still highly valued (Leung, 2001). High endorsement of connecting and meaning represented the fact that students' and their teachers' valued meaningful learning, which is advocated in Western cultures (Ausubel, 2000) and is inherent in traditional Chinese cultural thought. Students in both education systems engaged in meaningful learning through classroom activities that were thoughtfully designed by their teachers who viewed mathematics as a coherent system (Leung, 2001) and who were influenced by the ancient idea from the Confucian Analects (Confucius, n.d./1893): "learning without thought is labor lost; thought without learning is perilous."

\section{Instructional Strategies}

Both the mathematics content and the procedures or skills used to deal with the content are emphasized in East Asian classrooms (Zhang, Li, \& Tang, 2004). In the present study, all participants, with the exception of the Taiwanese students who endorsed both factors equally, valued concept connecting and firming more than outlining and problem-solving. This was especially true for the teachers, who placed more emphasis on developing students' understanding of mathematical concepts than their problem-solving skills when planning classes. This may result from the influence of the Western culture (Bryan et al., 2007; Leung, 2001). Regarding teaching method, all students and teachers endorsed detailed illustration the most, coinciding with the traditional Chinese idea regarding the role of teachers - to propagate, teach, and disabuse (Shao et al., 2013). Mathematics teachers in both education systems are still considered as experts, thus demonstrating the long-lasting influence of Confucian thought regarding the roles of teachers (Leung, 2001). Questioning and long-term tasks have been highly promoted in the curriculum reforms of the two education systems, where learning is considered learners' active construction rather than their 
passive reception. The degrees to which students and teachers endorsed these factors revealed the influence of Western culture (Leung, 2001; Zhao \& Ma, 2013). The teachers valued the two factors equally, whereas the students' perspectives revealed an intracultural difference. Taiwanese students endorsed questioning more than they did longterm task, whereas Chinese students preferred long-term task more than they did questioning. The reasons for Taiwan's situation may relate to that questioning is a feasible and commonly used approach to increase the interactions between teachers and students in mathematics classes. Long-term task is less used because it requires a considerable amount of time. Conducting the approaches embedded in this factor may cause teachers' failure of keeping up with the tight teaching schedule and a rush of instruction on some topics. This situation is not favoured by senior high school students in Taiwan. The Chinese situation may relate to that long-term task is rarely used in senior high school mathematics classes in mainland China and the students expect to have a mathematics class featured by considerable autonomy and less control (Bryan et al., 2007). Regarding problem solving, both sets of students and teachers valued multiple heuristics more than speedy challenge. The factor speedy challenge is embedded in traditional Chinese education, but its low endorsement revealed a change in perspective which may result from the influence of the Western culture. Both students and their teachers want problems to be solved through learning how to think about the problems as opposed to students being passive observers of teacher problem-solving demonstrations, usually made at a quick pace, even though the mathematics problems presented in classes, exercises, and exams are difficult and varied.

\section{Assessments}

Academic achievement is valued in traditional Chinese culture, and this serves as crucial motivation for learning (Leung, 2001), resulting in a considerable proportion of mathematics learning being examination-based. However, both students and their teachers in Taiwan and mainland China endorsed comprehension diagnoses more than they did performance demand. This may result from the influenced of the Western culture. From their perspectives, which might not coincide with real class practice (Chen, 2015), teachers should put more emphasis on tracking students' comprehension than on allowing for lots of examination-type practice. However, the students' higher endorsement of performance demand than that of their teachers may reflect their desire for high academic performance.

The perspectives of the teachers in Taiwan and mainland China reveal the possible mathematics teaching behaviors that can be employed in class, whereas the perspectives of the students provide the teachers with opportunities to adjust their instruction in a manner that fits the internationally prevailing student-centred perspectives. The present study revealed the students' weak endorsement of formal and symbolic representation (in the dimension representation), speedy challenge (in the dimension problem solving), and performance demand (in the dimension assessment) but also revealed that they endorsed these factors more strongly than their teachers. This may reflect the strong desire of some students for high academic performance and their higher acceptance of these factors than their teachers' anticipation. Regarding teaching practice when instructing these students, teachers can employ abstract representations and challenging content, and ask the students to complete heavy practice. International comparison studies have revealed that East Asian students are notorious for their high mathematics achievement but doubtful of the value of mathematics (e.g., TIMSS; Mullis, Martin, Foy, \& Hooper, 2016). Teachers in the two education systems should further consider whether their students care only about high achievement and should consider how they can help students recognize the value of mathematics. The students and teachers gave similar responses for the other 10 factors, both endorsing them. From the student-centred perspective, these factors and the corresponding mathematics teaching behaviors constitute part of ideal mathematics instruction and should be done in class. In addition, the teachers' endorsement shows the high likelihood that these factors are implemented in mathematics classes in Taiwan and mainland China because teachers in these countries are highly competent and thus capable of performing the teaching behaviors they intend to perform (Hsieh et al., 2011; Leung, 2006). The findings of this study thus reveal the status of mathematics classes, reflecting that in high-achieving East Asian countries in TIMSS and PISA (Mullis et al., 2016; OECD, 2016) such as Taiwan and mainland China, these classes adopt the perspectives of both traditional Chinese and Western cultures.

The framework developed in this study - including the facets, dimensions, ideal mathematics teaching behaviors - and students' and teachers' endorsements of those teaching behaviors can contribute to the field by provoking thinking and discussion to reveal the similarities and differences between frameworks and endorsed teaching behaviors in various cultures. Furthermore, the list of ideal mathematics teaching behaviors can be of practical use. A teacher can use the list to determine his or her students' endorsement of various mathematics teaching behaviors and thus understand whether his or her teaching meets students' expectations, enabling the teacher to adjust their mathematics instruction accordingly. 


\section{Limitations and Suggestions}

To collect large-scale data and make comparisons between two education systems, the present study employed a questionnaire survey as the research approach. Further qualitative research is required to investigate the connotations of each item in the questionnaire. Taking item PS5 as an example, this teaching behavior could be further investigated by exploring how much time teachers should give their students to think before giving an explanation and highlighting the differences for students with differing characteristics.

\section{CONCLUSION}

The present study identified 13 ideal mathematics instruction factors in six dimensions comprising three facets and discovered substantial intracultural similarities between Taiwan and mainland China. The factors of ideal mathematics teaching behaviors which were endorsed and not endorsed by senior high school students and their teachers revealed the influence of Western cultural thought on mathematics teaching after mathematics curriculum reforms in Taiwan and mainland China, and how traditional Chinese thought still influences education in these education systems. Compared with the educative views in Western countries, the views of the students and teachers from both education systems in this study exhibited no considerable intracultural differences. Because of the influence of Western cultures, simplification and concreteness, concrete and life-related representation, questioning, long-term tasks, and comprehension diagnoses were endorsed by both the students and their teachers. Connection and meaning, concept connecting and firming, outlining and problem solving, detailed illustration, and multiple heuristics are concepts long embedded in Chinese culture and were still endorsed by all groups. Formal and symbolic representation, speedy challenge, and performance demand are also embedded in traditional Chinese culture, but the emphasis on these factors has recently decreased. Among these factors, the students endorsed formal and symbolic representation and performance demand more than their teachers did, reflecting students' desire for high academic achievement, which is deeply rooted in Chinese culture.

\section{REFERENCES}

Ausubel, D. P. (2000). The acquisition and retention of knowledge: A cognitive view. Dordrect, Boston: Kluwer Academic Publishers. https:/ / doi.org/10.1007/978-94-015-9454-7

Bao, J. (2004). A comparative study on composite difficulty between new and old Chinese mathematics textbooks. In L. Fan et al. (Eds.), How Chinese learn mathematics: Perspectives from insiders (pp. 208-227). Singapore: World Scientific Publishing Co. Pte. Ltd. https:/ / doi.org/10.1142/9789812562241_0008

Bryan, C. A., Wang, T., Perry, B., Wong, N.-Y., \& Cai, J. (2007). Comparison and contrast: similarities and differences of teachers' views of effective mathematics teaching and learning from four regions. The International Journal on Mathematics Education, 39(4), 329-340. https:/ / doi.org/10.1007/s11858-007-0035-2

Cai, J. (2004). Why do US and Chinese students think differently in mathematical problem solving? Exploring the impact of early algebra learning and teachers' beliefs. Journal of Mathematical Behavior, 23(2), 135-167. https:/ / doi.org/10.1016/j.jmathb.2004.03.004

Cai, J. (2007). What is effective mathematics teaching? A study of teacher form Australia, Mainland China, Hong Kong SAR, and the United States. The International Journal on Mathematics Education, 39(4), 265-270. https:// doi.org/10.1007/s11858-007-0029-0

Cai, J., \& Wang, T. (2006). U.S. and Chinese teachers' conceptions and constructions of representations: A case of proportional reasoning. International Journal of Science and Mathematics Education, 4(1), 145-186. https:/ / doi.org/10.1007/s10763-005-9006-7

Cai, J., Perry, B., Wong, N.-Y., \& Wang, T. (2009). What is effective teaching? A study of experienced mathematics teachers from Australia, the mainland China, Hong Kong-China, and the United States. In J. Cai, G. Kaiser, B. Perry, \& N.-Y. Wong (Eds.), Effective mathematics teaching form teachers' perspectives (pp. 1-36). Rotterdam, the Netherlands: Sense Publishers.

Chen, J. (2015). Teachers' conceptions of approaches to teaching: A Chinese perspective. Asian-Pacific Education Researcher, 24(2), 341-351. https:/ / doi.org/10.1007/s40299-014-0184-3

Chen, J., Brown, G. T. L., Hattie, J. A. C., \& Millward, P. (2012). Teachers' conceptions of excellent teaching and its relationships to self-reported teaching practices. Teaching and Teacher Education, 28(7), 936-947. https:/ / doi.org/10.1016/j.tate.2012.04.006

Chen, P. Y. (2008). Strategic leadership and school reform in Taiwan: School effectiveness and school improvement. An International Journal of Research, Policy and Practice, 19(3), 293-318. https://doi.org/10.1080/09243450802332119 
Cohen, J. (1992). A power primer. Psychological Bulletin, 112, 155-159. https:/ / doi.org/10.1037/0033-2909.112.1.155

Confucius. (1983). Confucian Analects (J. Legge. Trans.) Retrieved from https://ctext.org/analects/wei-zheng (Original work published n.d.).

Council of Chief State School Officers. (2011). Interstate teacher assessment and support consortium (INTASC) model core teaching standards: A resource for state dialogue. NW, Washington, DC: Author.

Farrell, D., \& Grant, A. (2005). Addressing China's looming talent shortage. Retrieved from https://goo.gl/Mx9s3z

Flora, D. B., \& Curran, P. J. (2004). An empirical evaluation of alternative methods of estimation for confirmatory factor analysis with ordinal data. Psychological Methods, 9(4), 466-491. https://doi.org/10.1037/1082989X.9.4.466

Hsieh, F.-J. (1997). 國中數學新課程精神與特色 [The spirits and the characteristics of new lower secondary mathematical curriculum]. Science Education Monthly, 197, 45-55.

Hsieh, F.-J. (2012). 國高中數學教學專業知能指標 [Indicators of professional mathematics teaching competence at the secondary school level]. Secondary Education, 63(3), 30-47.

Hsieh, F.-J., Law, C. K., Shy, H. Y., Wang, T. Y., Hsieh, C. J., Tang, S.-J. (2011). Mathematics Teacher Education Quality in TEDS-M --Globalizing the views of future teachers and teacher educators. Journal of Teacher Education, 62(2), 172-187. https:/ / doi.org/10.1177/0022487110390819

Hsieh, F.-J., Shy, H.-Y., \& Wang, T.-Y. (2015, May). Factors for being a great mathematics teacher regarding teaching devices - from students' perspectives. Paper presented at The 7th ICMI - East Asia Regional Conference on Mathematics Education, Cebu, Philippines.

Kaiser, G., \& Vollstedt, M. (2007). Teachers' views on effective mathematics teaching: Commentaries from a European perspective. The International Journal on Mathematics Education, 39(4), 341-348. https:// doi.org/10.1007/s11858-007-0036-1

Kane, R. G., \& Maw, N. (2005). Making sense of learning at secondary school-involving students to improve teaching practice. Cambridge Journal of Education, 35(3), 311-322. https:/ / doi.org/10.1080/03057640500319024

Kaur, B. (2009). Characteristics of good mathematics teaching in Singapore grade 8 classrooms: A juxtaposition of teachers' practice and students' perception. The International Journal on Mathematics Education, 41(3), 333-347. https:/ / doi.org/10.1007/s11858-009-0170-z

Lee, H. H., Kim, L. G. M., \& Chan, L. L. (2015). Good teaching: what matters to university students. Asia Pacific Journal of Education, 35(1), 98-110. https:/ / doi.org/10.1080/02188791.2013.860008

Leong, K. E. (2013). Factors that influence the understanding of good mathematics teaching. Eurasia Journal of Mathematics, Science \& Technology Education, 9(3), 319-328. https:/ / doi.org/10.12973/eurasia.2013.939a

Leong, K. E. (2015). What are the important attributes of mathematics teaching? Asia-Pacific Education Researcher, 24(1), 211-223. https:/ / doi.org/10.1007/s40299-014-0173-6

Leu, Y.-C., \& Wu, C.-J. (2005). Investigation on an elementary teacher's mathematics pedagogical values through her approach to students' errors. In H. L. Chick \& J. L. Vincent (Eds.), Proceedings of the 29th Conference of the International Group for the Psychology of Mathematics Education (pp. 249-256).

Leung, F. K. S. (2001). In search of an East Asian identity in mathematics education. Educational Studies in Mathematics, 47(1), 35-51. https:/ / doi.org/10.1023/A:1017936429620

Leung, F. K. S. (2006). Mathematics education in East Asia and the West: Does culture matter? In F. K. S. Leung, K.D. Graf, \& F. J. Lopez-Real (Eds.), Mathematics education in different cultural traditions - A comparative study of East Asia and the West (pp.21-50). NY: Springer. https:/ / doi.org/10.1007/0-387-29723-5

Li, Y. (2011). Elementary teachers' thinking about a good mathematics lesson. International Journal of Science and Mathematics Education, 9(4), 949-973. https:/ / doi.org/10.1007/s10763-010-9263-y

Lin, P.-J., \& Li, Y. (2009). Searching for good mathematics instruction at primary school level valued in Taiwan. The International Journal on Mathematics Education, 41(3), 363-378. https:/ / doi.org/10.1007/s11858-009-0175-7

Lin, T.-B., Wang, L.-Y., Li, J.-Y., \& Chang, C. (2014). Pursuing quality education: The lessons from the education reform in Taiwan. Asian-Pacific Education Researcher, 23(4), 813-822. https://doi.org/10.1007/s40299-0130135-4

Ministry of Education (2008). 國民中小學九年一貫課程綱要數學學習領域[Grade 1-9 curriculum guidelines Mathematics]. Retrieved from http://teach.eje.edu.tw/data/files/class_rules/math.pdf

Mullis, I. V. S., Martin, M. O., Foy, P., \& Hooper, M. (2016). TIMSS 2015 International Results in Mathematics. Chestnut Hill, MA: TIMSS \& PIRLS International Study Center, Boston College. 
National Academy for Educational Research (2016). 十二年國民基本教育課程綱要課程綱要 - 數學領域 [12-year Basic Education curriculum guidelines - $\quad$ Mathematics]. Retrieved from https:/ / www.naer.edu.tw/ezfiles/0/1000/attach/37/pta_10147_1655251_02807.pdf

OECD (2016, December, 6). PISA 2015 Results (Volume I): Excellence and Equity in Education. Retrieved from https://ppt.cc/fxFoKq

Pang, J. (2009). Good mathematics instruction in South Korea. The International Journal on Mathematics Education, 41(3), 349-362. https:// doi.org/10.1007/s11858-009-0169-5

Perry, B. (2007). Australian teachers' views of effective mathematics teaching and learning. The International Journal on Mathematics Education, 39(4), 271-286. https:/ / doi.org/10.1007/s11858-007-0032-5

Pólya, G. (1973). How to solve it (2nd ed.). Princeton, New Jersey: Princeton University Press.

Sahin, A., \& Adiguzel, T. (2014). Effective teacher qualities from international mathematics, science, and computer teachers' perspectives. Eurasia Journal of Mathematics, Science E Technology Education, 10(6), 635-646. https:/ / doi.org/10.12973/eurasia.2014.1119a

Shao, G., Fan, Y., Huang, R., Ding, E., \& Li, Y. (2013). Mathematics classroom instruction in China viewed from historical perspective. In Y. Li \& R. Huang (Eds.), How Chinese teach mathematics and improve teaching (pp.1128). New York, NY: Routledge.

Shepard, L. A. (2000). The role of assessment in a learning culture. Educational Researcher, 29(7), 4-14. https:/ / doi.org/10.3102/0013189X029007004

Skemp, R. R. (1989). Mathematics in the primary school. London, UK: Routledge.

Smith, E., \& Gorard, S. (2006). Pupils' views on equity in schools. Compare: A Journal of Comparative and International Education, 1(36), pp. 41-56. https:/ / doi.org/10.1080/03057920500382465

Stigler, J. W., \& Hiebert, J. (1999). The teaching gap: Best ideas from the world's teachers for improving education in the classroom. New York: Free Press.

Tseng, H.-H. (2008). 高中優秀數學教師提供學生有意義學習之情形研究 [The research of the phenomena of senior high school excellent mathematics teachers' providing students meaningful learning] (Master's thesis). National Taiwan Normal University, Taipei.

Wang, J., \& Wang, X. (2012). Structural equation modeling: Applications using Mplus. United Kingdom: Higher education press. https:/ / doi.org/10.1002/9781118356258

Wang, T., \& Cai, J. (2007a). Chinese (Mainland) teachers' views of effective mathematics teaching and learning. The International Journal on Mathematics Education, 39(4), 287-300. https:/ / doi.org/10.1007/s11858-007-0030-7

Wang, T., \& Cai, J. (2007b). United States teachers' views of effective mathematics teaching and learning. The International Journal on Mathematics Education, 39(4), 315-327. https:/ / doi.org/10.1007/s11858-007-0031-6

Williams, B., Brown, T., \& Onsman, A. (2010). Exploratory factor analysis: A five-step guide for novices. Australasian Journal of Paramedicine, 8(3), 1-13. https:// doi.org/10.33151/ajp.8.3.93

Wong, J. L. N. (2010). Searching for good practice in teaching: a comparison of two subject-based professional learning communities in a secondary school in Shanghai. Compare: A Journal of Comparative and International Education, 5(40), pp. 623-639. https:// doi.org/10.1080/03057920903553308

Wong, N.-Y. (2007). Hong Kong teachers' views of effective mathematics teaching and learning. The International Journal on Mathematics Education, 39(4), 301-314. https:/ / doi.org/10.1007/s11858-007-0033-4

Yang, X. (2013). Investigation of junior secondary students' perceptions of mathematics classroom learning environments in China. Eurasia Journal of Mathematics, Science E Technology Education, 9(3), 273-284. https:/ / doi.org/10.12973/eurasia.2013.935a

Zhang, D., Li, S., \& Tang, R. (2004). The "two basics": Mathematics teaching and learning in Mainland China. In L. Fan et al. (Eds.), How Chinese learn mathematics: Perspectives from insiders (pp. 189-207). Singapore: World Scientific Publishing Co. Pte. Ltd. https://doi.org/10.1142/9789812562241_0007

Zhao, D., \& Ma, Y. (2007). A qualitative research on evaluating primary mathematics lessons. Journal of Mathematics Education, 16(2), 71-76.

Zhao, D., \& Ma, Y. (2013). Features of "excellent" lessons valued before and after the implementation of new curriculum standards. In Y. Li \& R. Huang (Eds.), How Chinese teach mathematics (pp. 134-149). New York, NY: Routledge.

\section{http://www.ejmste.com}

